\title{
Achenbach's Syndrome in a 30-year-old Healthy Woman
}

\author{
Jun Suzuki
}

Key words: Achenbach's syndrome, hematoma

\author{
(Intern Med 58: 1807, 2019)
}

(DOI: 10.2169/internalmedicine.2263-18)

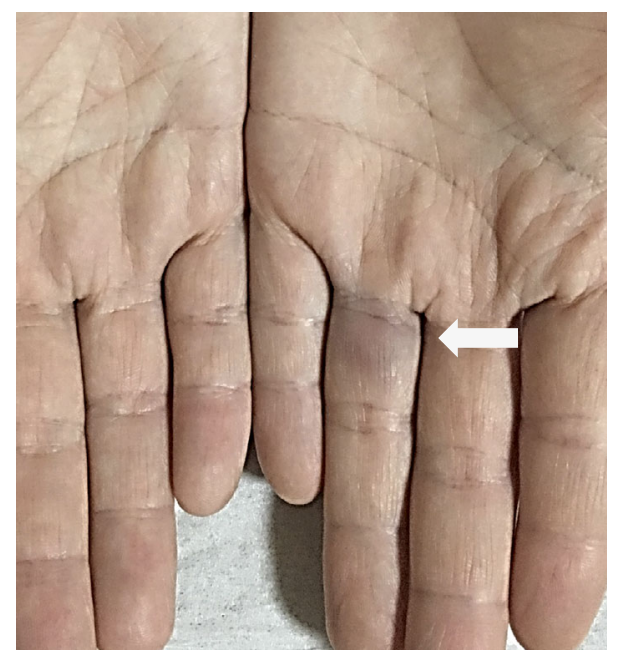

Picture. larly in women. Middle-aged women often developed this syndrome; however, a few reports have shown that even patients under 30 years of age can develop it $(1,2)$. Although this syndrome might be induced by external force, patients without any identifiable cause often develop this syndrome (2). This syndrome is characterized by exacerbation and remission without treatment and is diagnosed by the exclusion of diseases, such as trauma, vasculitis, and atherosclerosis $(1,2)$. It may therefore be difficult to accurately diagnose this condition. Although the symptoms often disappear within several days, a few cases have demonstrated relapse $(1,2)$. The present case emphasizes the importance of considering Achenbach's syndrome in the differential diagnosis of women presenting with swollen fingers in the absence of any other risks for bleeding.

The author states that he has no Conflict of Interest (COI).

\section{References}

1. Cowen R, Richards T, Dharmadasa A, Handa A, Perkins JM. The acute blue finger: management and outcome. Ann R Coll Surg Engl 90: 557-560, 2008.

2. Takeuchi H, Uchida HA, Okuyama Y, Wada J. Acute idiopathic blue fingers: a young man with Achenbach's syndrome. BMJ Case Rep 2016: 214491, 2016.

The Internal Medicine is an Open Access journal distributed under the Creative Commons Attribution-NonCommercial-NoDerivatives 4.0 International License. To view the details of this license, please visit (https://creativecommons.org/licenses/ by-nc-nd/4.0/). 